\title{
LA REINDIANIZACIÓN DEL GOBIERNO MUNICIPAL EN HUIXTÁN: CAMBIOS, PERSISTENCIAS Y RESISTENCIAS EN UN MUNICIPIO DE LOS ALTOS DE CHIAPAS ${ }^{1}$
}

\author{
José Manuel Martín Pérez \\ manuel.martn6@gmail.com
}

Universidad Autónoma de Chiapas (UNACH)

\section{RESUMEN}

En este texto se da cuenta de la constante configuración y reconfiguración del gobierno municipal de Huixtán, Chiapas. Para tal explicación, considero necesario partir de distintos momentos, con base en su contexto más amplio, en los que es posible observar tales cambios. Así, como parte de un ciclo no evolucionista, tomé aquellos que incluyeran procesos de reindianización, desindianización y una nueva reindianización del gobierno municipal huixteco. Esto último, acontecido en la coyuntura zapatista, después de 1994, donde se enfatiza la renovación de los vínculos entre las autoridades municipales y los ancianos principales, así como en la revitalización del sentido religioso de ciertas prácticas en el ejercicio del gobierno municipal. Prácticas y relaciones que son características de los gobiernos indígenas de los Altos de Chiapas.

Palabras clave: gobierno indígena, reindianización, EZLN, Huixtán.

\section{RE-INDIGENIZATION OF THE MUNICIPAL GOVERNMENT IN HUIXTAN: CHANGE, PERSISTENCE AND RESISTENCE IN A CHIAPANECAN MUNICIPALITY IN LOS ALTOS DE CHIAPAS}

\begin{abstract}
This text narrates the constant configuration and reconfiguration of the municipal government of Huixtan, Chiapas. For this explanation, it is necessary to use different chronological moments as a point of departure. This broader context allows the changes to be observed. As part of a non-linear cycle, moments including re-indigenization, de-indigenization and a new re-indigenization processes of the municipal government of Huixtan were selected for study. The re-indigenization process occurring after 1994, during the Zapatista juncture, emphasizes the renewal of the bond between municipal authorities and the main elders, as well as the revitalization of religious meaning in certain practices during the exercise of municipal government. Both these practices and the aforementioned relationships characterize indigenous governments of los Altos de Chiapas.
\end{abstract}

Key words: indigenous government, re-indigenization, EZLN, Huixtan.

\footnotetext{
${ }^{1}$ Agradezco las atinadas observaciones y sugerencias que la maestra Aracely Burguete Cal y Mayor (Centro de Investigaciones y Estudios Superiores en Antropología Social [CIESAS] Sureste) realizó al presente texto. Asimismo, a los dictaminadores por sus puntuales comentarios y sugerencias que apoyaron para superar las debilidades de una primera versión. De cualquier manera, lo expuesto y las limitaciones son mi responsabilidad única. Esta investigación fue financiada a través de una beca proporcionada por el CIESAS durante el periodo 2011-2012.
} 


\section{INTRODUCCIÓN}

A mediados de la década de 1950, Gonzalo Aguirre Beltrán describió al «gobierno indígena» como una institución cuyas características políticas y religiosas tenían fuerte arraigo en todo el altiplano central de Chiapas y en algunas otras regiones de México. De acuerdo con sus planteamientos, dicha institución se conformaba con la coexistencia de cargos, instituciones y cuerpos de autoridades que tenían su origen tanto en la época prehispánica como en la colonial. La posición evolucionista de Aguirre Beltrán preveía que estas formas de gobierno dejarían de existir tras la instauración del municipio libre y del ayuntamiento municipal, y señalaba un proceso de abandono paulatino que estaban sufriendo esas «formas de gobierno indígena», debido a una dinámica de «aculturación» que daba paso al establecimiento pleno del ayuntamiento municipal, de sus funcionarios y de sus labores administrativas (Aguirre 1991:100). Sin embargo, la realidad parece haber ido más allá de las predicciones de ese autor y de otros antropólogos que estudiaron los gobiernos indígenas en el siglo XX (Pozas 1987). Y es que, al contrario de lo previsto, los gobiernos indígenas están presentes en nuestros días. Si bien en algunos casos las estructuras de tales gobiernos fueron debilitadas, sus tareas y prácticas de gobernabilidad interna (con características político-religiosas) no solo no desaparecieron, sino que en los albores del siglo XXI atraviesan por fuertes procesos de revitalización y resignificación, y puede observarse incluso un proceso de indianización de instituciones del Estado como el ayuntamiento municipal. En este sentido, cabe preguntarse si, en efecto, estos procesos de reconfiguración de las instituciones de gobierno indígena corresponden al presente o bien han sido un fenómeno recurrente, cíclico, a lo largo de la historia, que hubiera permanecido invisibilizado por enfoques teóricos de la antropología social cuya perspectiva evolucionista advertía inexorables procesos de «ladinización», como observó Julio de la Fuente (1990) para el caso del municipio de Huixtán.

Al respecto, la mirada de Araceli Burguete (2011) permite explicar este proceso de transformaciones, configuración y reinvención de los gobiernos indígenas. Dicha autora argumenta que los pueblos indígenas -tras el enérgico proceso de colonización al que fueron sometidos desde el siglo XVI- han sido parte de contextos más extensos en su propio devenir, lo cual no excluye su relación con el Estado y con su institucionalidad dentro de sus territorios. En este sentido, asevera que así como el Estado ha tenido cambios a lo largo de su historia, las instituciones que lo conforman también se han transformado como resultado de su interacción con los colectivos indígenas, lo que ha dado lugar, al mismo tiempo, a configuraciones particulares del Estado en los contextos indígenas latinoamericanos. De esta forma se puede identificar la presencia del «gobierno indígena» en diversos países de la región; y aunque tengan características comunes, cada uno de ellos es específico. De tal forma que, como resultado de esas configuraciones, los gobiernos indígenas no tienen una composición homogénea, cada uno posee una singularidad cultural, ya sea en sus instituciones, composición, prácticas, discursos y objetos simbólicos, con los que dan sentido a su diferencia cultural (Burguete 2011:73). Al respecto, la autora refiere:

[...] los llamados «gobiernos indígenas» son construcciones históricas resultado de una compleja mixtura amasada con componentes que provienen de las instituciones de gobierno nativo y aquellos formados por el orden colonial, primero, y por los Estados nacionales, después. El «gobierno indígena» es un resultado histórico producto de un diálogo tenso entre los pueblos indígenas y los distintos intereses y tensiones que lo cruzan, tanto hacia adentro como con otros diálogos, alianzas, presiones y disputas, que sostienen con actores externos; entre éstos con las instituciones estatales, en sus distintos momentos históricos. El municipio ha sido una institución clave en los procesos de configuración del gobierno indígena; de hecho, podemos afirmar que la voluntad gubernamental ha sido la de municipalizar al gobierno indígena, pero este se ha configurado en resistencia, marcando siempre la diferencia. Para adecuarse a los cambios en el Estado [...] las instituciones de gobierno indígena han sido de igual manera siempre cambiantes (Burguete 2011:46). ${ }^{2}$

Para esta autora no tiene solidez la argumentación de que las instituciones de gobierno indígenas sean vistas como entes ahistóricos, aislados del contexto social y del Estado. Desde su perspectiva, las relaciones sociopolíticas cotidianas entre el Estado y los pueblos indígenas han dado lugar a que las instituciones indígenas cambien, resistan y persistan hasta nuestros días. Así, señala lo siguiente:

[...] con cada nueva institución estatal establecida sobre territorio indígena, suele darse el inicio de una lucha desde los colectivos indígenas para intentar, otra vez, (re)significar, et-

\footnotetext{
${ }^{2}$ Las cursivas son mías.
} 
nizar, las instituciones del Estado; y así convertir dicha institución «ajena» en «apropiada». Lucha histórica que nos ayuda a comprender la persistencia de los pueblos indígenas, siempre reinventados, hasta nuestros días (Burguete 2011:69).

Esto solo es posible en la medida en que los pueblos indígenas tomen parte en la dinámica de los distintos procesos sociales. Y aunque se trata de un fenómeno local, siempre será necesario analizarlo en un contexto más extenso. En términos bonfilianos, la autora habla de imposición, reelaboración y apropiación recíproca tanto de las instituciones indígenas como del Estado. Por ello - continúa- es posible hablar de un curso dialéctico en el que simultáneamente se han producido procesos de «indianización del gobierno municipal» así como de una «municipalización del gobierno indígena», resultado de la flexibilidad de la institucionalidad indígena y de su estrecha relación con el orden jurídico estatal: haciendo posible, paralelamente, la modificación del Estado al realizar cambios en su organización y en su perspectiva cultural (Burguete 2011:41).

Es importante decir que esas transformaciones ocurren en procesos de «empoderamiento» ${ }^{3}$ de los pueblos indígenas que otorgan «capacidad» y «voluntad» consciente para reelaborar las instituciones estatales, mediante complejos procesos de apropiación (no siempre apacibles), que la autora denomina indianización, con el objetivo de resistir políticamente y hacer persistir su diferencia cultural frente a un Estado históricamente integracionista con el cual mantiene constantes disputas en la arena política (Burguete 2011:40).

Con base en estas referencias teóricas retomaremos la experiencia de Huixtán, ${ }^{4}$ un municipio del

\footnotetext{
${ }^{3}$ Aunque existen otros términos en español para expresar el «empoderamiento», ninguno de ellos transmite cabalmente la idea que alimenta este otro, a saber: señalar 'acción en torno al poder' que presume la existencia de sujetos como agentes activos, así como cambios de cultura, que en conjunto hagan posible la acción de «empoderar» a los actores sociales que, por diversas razones, carecen de poder (como los indígenas) y aspiran a tenerlo a través de la participación (Burguete y Torres 2007:140). Para conocer más ampliamente sobre las tendencias de empoderamiento indígena en los Altos de Chiapas, véase Burguete 1999a.

${ }^{4}$ Huixtán es uno de los municipios de la región de los Altos de Chiapas. Se encuentra ubicado entre los límites al norte con Tenejapa y Oxchuc, al este con Chanal, al sur con Amatenango del Valle y al oeste con San Cristóbal de Las Casas. Cuenta con una extensión territorial de $181.3 \mathrm{~km}^{2}$, lo que representa $4.80 \%$ de dicha región y $0.23 \%$ del estado de Chiapas (Sánchez 1997).
}

altiplano central chiapaneco cuya institución de gobierno municipal ha sido atravesada por importantes reconfiguraciones en las últimas décadas y a lo largo de su historia, razón por la cual considero de interés antropológico dar cuenta de tales procesos.

\section{LA TEMPRANA DESINDIANIZACIÓN DEL AYUNTAMIENTO MUNICIPAL EN HUIXTÁN DURANTE EL SIGLO XIX}

La colonización española durante el siglo XVI marcó un severo trastorno en la vida de los pueblos originarios que llevó a la transformación de sus formas de vida, sus instituciones y su territorio. Resultó entonces que las localidades prehispánicas de las antiguas «provincias» integraron una nueva institución de gobierno: la República de indios, para fines prácticos en su administración política y tributaria durante la Colonia. En los decretos eclesiásticos para la Nueva España, a mediados del siglo XVI, se obligaba a los indios a reubicarse en poblados cercanos y a no salir de su «provincia». Asimismo, se decretó la necesidad de ser sujetos de evangelización y permitir la instauración de templos católicos en nuevas poblaciones de diseño urbano, al tiempo de aceptar gobernadores -indios cristianizados elegidos por frailes dominicos- como autoridades en los denominados Cabildos Indígenas (Lenkersdorf 2001).

Durante este periodo (finales del siglo XVI y principios del XVII) Huixtán pudo haber tenido un gobierno en «manos de sus propios habitantes», «de tipo concejil», y «secretarios indígenas locales» con una permanencia de «un año en el cargo», tal y como lo ordenaba el decreto de la Corona para los pueblos mayas de Chiapas de entonces, aunque ese gobierno colonial asumiera la dificultad de estar obligado a cumplir los mandatos de «cualquier autoridad española», como sucedió en el vecino Tehultepeque (hoy Oxchuc) hacia 1674 (Lenkersdorf 2001, Gómez et al. 2010). De esa forma fueron elegidos «los coroneles», «alcaldes» y «regidores» para responsabilizarlos de acatar los mandatos dictados por la Corona y la Iglesia.

Tras los cambios que siguieron a este proceso las comunidades indígenas sufrieron transformaciones, $\mathrm{y}$ en los inicios del siglo XIX fueron impactadas por otro enérgico proceso de reconfiguración política. En México, la instauración del ayuntamiento gaditano durante la república decimonónica, posterior a 
la guerra de Independencia, desplazó a la República de Indios (cuando esta ya se había significado como una institución «apropiada» luego de permanecer por siglos en manos indígenas); se eliminó la división de las dos Repúblicas coloniales, y se establecieron ayuntamientos como instituciones de gobierno local en las nacientes municipalidades. Esta situación minó toda posible continuidad a los antiguos cabildos coloniales como gobiernos indígenas, y fueron relegados desde entonces a la clandestinidad. Sumado a ello, la forja por la separación entre el Estado y la Iglesia durante la promulgación de las Leyes de Reforma, a mediados del siglo XIX, debilitó a las instituciones religiosas en zonas indígenas, y respecto de la Iglesia católica esta sufrió un abandono y una separación parciales en el último tercio de ese siglo XIX, lo que posibilitó la revitalización sincrética de la religión de los «naturales» (Palomo 2009). En Huixtán este hecho significó también la transformación de la cofradía católica Nuestra Señora de La Luz, que había sido instaurada en el siglo XVIII (12 de agosto de 1790), y se articuló posteriormente con algunos cargos de la estructura del gobierno colonial hacia finales de 1870 (Palomo 2009:112). Esta relación se produjo en un contexto de amenaza a las instituciones de gobierno indígena, cuando el ayuntamiento municipal pasó a manos de «ladinos terratenientes» locales.

La presencia ladina ha sido central en Huixtán, con su aparición temprana, desde el siglo XVIII, por motivo de la producción de trigo que alimentaba a la creciente población criollo-mestiza que se estableció en la región Altos (Wasserstrom 1989). Por esa presencia ladina Huixtán tuvo relevancia en la geopolítica regional. Si bien el territorio no siempre tuvo la categoría de municipio, fue considerado desde el principio como un pueblo de importancia, y para tal efecto tuvo reconocimiento de cabecera de villa y provincia, y más tarde se le dio la categoría de subdelegación. Por esta centralidad de la presencia ladina en el municipio, desde muy temprano los indígenas fueron desplazados del ayuntamiento, y se produjo de ese modo un proceso de desindianización. No obstante, Huixtán vivió en la incertidumbre en cuanto al reconocimiento de su categoría de municipio. Por ejemplo, entre los años 1858 y 1881 desapareció del mapa municipal, y no reapareció hasta 1882 . Pero a partir de 1930 adquiere la categoría municipal, y así la mantiene desde entonces (INEGI 1997).

\section{LA REINDIANIZACIÓN DEL AYUNTAMIENTO MUNICIPAL EN HUIXTÁN (1938)}

Las frecuentes descalificaciones hacia el Cabildo Colonial, el debilitamiento de la Iglesia, la revitalización de la religiosidad indígena con la ruptura definitiva de las Repúblicas, la instauración del ayuntamiento gaditano y el debilitamiento de la institución del Cabildo sentaron las bases para que los ladinos que habitaban Huixtán tomaran el control del ayuntamiento municipal en sus manos y desplazaran a las autoridades indígenas. Estas se replegaron en las pequeñas comunidades o parajes. En los primeros años del siglo XX el nuevo municipio libre fue disputado entre «ladinos pobres» $\mathrm{y}$ 《ladinos terratenientes». Pero al concluir los años cuarenta ocurriría un proceso de reindianización del ayuntamiento municipal, y entonces los ladinos terratenientes fueron desplazados de los principales cargos de gobierno.

Hacia el primer tercio del siglo XX, durante el periodo de gobierno del general Lázaro Cárdenas (1934-1940), se abrió una coyuntura que permitió a los indígenas retomar el control de su ayuntamiento municipal. Este proceso de empoderamiento por motivo de recuperación del gobierno local en los municipios se generalizó en toda la región de los Altos a inicios de 1939 (iniciando con demandas agrarias), con apoyo de funcionarios locales liderados por Erasto Urbina (Xalik). El proceso que consolidó la «reindianización» de los ayuntamientos municipales (el ascenso indígena al ayuntamiento constitucional) tuvo en cada uno de los municipios alteños características peculiares. ${ }^{5}$ En Huixtán este suceso se concretó en el año de 1938, pero estuvo precedido por una alianza peculiar que había ocurrido años atrás cuando tsotsiles y ladinos pobres se aliaron con el fin de destituir del poder político a los ladinos terratenientes. Este triunfo se consolidó al surgir el primer presidente municipal tsotsil del siglo XX: Pedro Huet Gómez, originario de K'ana (hoy ejido Lázaro Cárdenas, Chilil), quien fue electo mediante procedimiento de asamblea. Sin embargo, las políticas integracionistas de la época establecieron la figura de «secretario municipal ladino» -cargo que sería monopolizado por los ladinos de Huixtán- para subordinar de nuevo al ayuntamiento municipal indígena.

\footnotetext{
${ }^{5}$ Véase el caso del municipio de Chamula ampliamente documentado por Jan Rus (2004).
} 
Así, aunque el ayuntamiento municipal constitucional quedó en manos de los indígenas, era el secretario municipal quien tomaba las decisiones.

Con la indianización del ayuntamiento municipal constitucional, los indígenas como gobierno y, en consecuencia, el gobierno indígena, se integraría desde entonces con dos cuerpos de autoridades que funcionarían de manera paralela: el ayuntamiento constitucional y el ayuntamiento tradicional, llamado «ayuntamiento regional» en Huixtán. Al respecto un registro etnográfico dice: «en Huistán, como en otros pueblos indígenas de Chiapas, existen dos ayuntamientos. Uno, constitucional, propio del sistema político nacional, y otro, tradicional, exclusivo de la comunidad nativa y cuya jurisdicción excluye al sector no indio del municipio» (Salmerón 1964:198).

Esta división no significaba, sin embargo, una ruptura. En el contexto del fin del cardenismo, el ayuntamiento constitucional indígena fue despojado de su capacidad de gestión, la cual permaneció en manos del secretario municipal ladino. Las funciones del presidente municipal quedaron otra vez unidas a las del ayuntamiento tradicional, y el gobierno indígena se integró con dos cuerpos de autoridades. En esos años, las autoridades del ayuntamiento municipal «hacían» lo que les solicitaban los funcionarios del ayuntamiento tradicional o regional, se sumaban a tareas religiosas y ceremonias ancestrales y se desentendían de sus responsabilidades políticas y administrativas, las cuales eran asumidas por el secretario municipal ladino.

Esta situación perduró hasta 1951, cuando llegó a San Cristóbal de Las Casas el Centro Coordinador Tsotsil-Tseltal (CCT-T), dependiente del Instituto Nacional Indigenista (INI), lo cual volvió a impactar la configuración del gobierno indígena. El ayuntamiento municipal indígena encontró nuevo soporte para su continuidad política y administrativa en el altiplano chiapaneco y para intentar despojarse de la figura del secretario municipal, así como del poder económico ladino en general.

A partir de esta época la relación entre los municipios indígenas de Chiapas y el Estado mexicano forma otra vez parte de la política oficial y el CCT-T vuelve nuevamente la vista hacia las comunidades indígenas «progresistas», es decir, no tradicionalistas, aquellas que fueron conformadas como ejidos durante el cardenismo. En Huixtán esto significó la vuelta del Estado hacia el ejido Lázaro Cárdenas
(Chilil) pues este había sido el primero conformado en el municipio. Durante el periodo entre los años cincuenta y sesenta el ayuntamiento municipal pasó de ser una mera «superposición» a apropiarse incluso de su significación: ocurrió un proceso de internalización y se estableció de manera firme en la vida política indígena, donde comenzó a ganar terreno, dadas sus atribuciones. Y fue estableciéndose con mayor legitimidad entre tsotsiles y tseltales, quienes con apoyo del CCT-T comenzaban a tomar el control de su ayuntamiento municipal. Vale recordar que en esa época, tanto el ayuntamiento municipal como los principaletik 'ancianos principales' mantenían fuertes lazos e influencia de uno sobre el otro, esto a finales de los años cincuenta (Miller 1959).

Así, aunque al finalizar el siglo XIX el gobierno indígena de Huixtán se había municipalizado, no sería hasta la primera mitad del siglo XX cuando el gobierno municipal atravesaría por un complejo y paulatino proceso de «re-apropiación/indianización»y comenzaría a conjuntar una nueva institución que dio como resultado una suerte de ayuntamiento indígena $^{6}$ en el que todos los funcionarios eran tsotsiles (aun cuando hablamos de un municipio pluriétnico tsotsil y tseltal) y cuyas prácticas sociales y discursos descansaban entonces sobre un pensamiento político y religioso ancestral de carácter comunitario.

\section{TIEMPOS DE CRISIS: DESINDIANIZACIÓN DEL AYUNTAMIENTO INDÍGENA HUIXTECO (1982)}

Aunque la economía había mejorado en la región entre las décadas de 1940 a 1960, impulsada por el constante flujo migratorio de tsotsiles y tseltales a las fincas cafetaleras del Soconusco, durante la década de 1960 a 1970 las oportunidades laborales decayeron fuertemente en aquella zona, tras la incursión cada vez mayor de mano de obra de indígenas guatemaltecos (Rus y Wasserstrom 1980). Aunada a ello, la construcción de la carretera internacional en 1974 abrió una brecha hacia una economía de mercado más extensa con el exterior, que trajo consigo com-

\footnotetext{
${ }^{6} \mathrm{El}$ ayuntamiento indígena «se integra por la suma y reacomodo entre cargos y funciones del ayuntamiento decimonónico y de los que establece la Ley Orgánica municipal en el siglo $\mathrm{XX}$. En Chiapas el ayuntamiento indígena es un tipo específico de gobierno local, que funciona por la vía de los hechos y no tiene reconocimiento legal» (Burguete y Torres 2007:92).
} 
petencia en los precios de productos traídos de otras regiones, como el del trigo, que por ser inferior al del producto local ocasionó un rápido desplazamiento de este último y una severa crisis en el municipio, cuya economía dependía casi por completo de los cultivos y la comercialización del grano. Esta situación detonó la caída de la economía en el municipio y llevó al debilitamiento definitivo del poder económico (y político) ladino en Huixtán que se había restablecido desde finales de 1940. Se acabó de ese modo con el monopolio comercial del grano (Rus y Wasserstrom 1980, Moguel y Parra 1998). ${ }^{7}$ En forma adicional a ese contexto económico que afectó a indígenas y ladinos, las tensiones sociopolíticas suscitadas por las incursiones religiosas (presbiteriana y de la "pastoral liberadora») y el surgimiento de una nueva generación de líderes, ${ }^{8}$ encabezada por promotores/maestros del Instituto Nacional Indigenista (INI) y por jóvenes catequistas con importante formación política crítica, impulsarían, a lo largo y ancho del altiplano central, fuertes cambios políticos durante la década de 1970 a 1980, tiempo en que existían importantes movimientos indígenas y campesinos con demandas agrarias e inconformes con el manejo de la vida política de sus municipios (De Vos 1997).

En este contexto sociopolítico de inicios de los ochenta, por vez primera un profesor trilingüe (tsotsil-tseltal-español), formado entre los promotores del Instituto Nacional Indigenista (INI), ocupó el cargo

\footnotetext{
${ }^{7}$ Para el año de 1950, al realizar algunas comparaciones de los municipios que producían trigo de temporal en la región, Huixtán fue catalogado como el de mayor producción en la región, superado solo por Amatenango en la obtención de trigo de riego. Este último municipio, aunque contaba con 185 hectáreas de riego, contra 208 de Huixtán, producía 157 toneladas (contra 99 de Huixtán). Para 1970, el conteo de la producción de trigo en la región casi desapareció al comenzar a contabilizarse junto al renglón de «otros cultivos» (Moguel y Parra 1998:88).

${ }^{8}$ Es importante mencionar que los cambios sociopolíticos en Huixtán y en la región, a lo largo del siglo XX, al menos, responden también a la presencia de actores locales claves en dichos procesos. Sobre este asunto, existen minuciosos análisis para la región de estudio como los realizados por Henning Siverts (1964 y 1965) para el caso de dos municipios tseltales vecinos a Huixtán (Oxchuc y Cancuc). En sus escritos dicho autor da cuenta de la importancia que tiene lo que él denomina «liderazgos» indígenas en los procesos políticos locales y cómo estos hilvanan cambios importantes en la estructura de gobierno indígena local alentados e impulsados por múltiples factores, sean políticos, religiosos o económicos (o la suma de todos ellos). Agradezco a Leif Korsbaek por haberme compartido las traducciones de los textos de Henning Siverts aquí citados.
}

de presidente municipal, elegido mediante asamblea (plebiscito) en la cabecera municipal. Pedro García Martínez (1980-1982), una vez en funciones, invitó a Pedro García Huacash a tomar el cargo de juez municipal, atraído por las capacidades personales de liderazgo y compromiso que había mostrado con el trabajo pastoral, como catequista, en el municipio. La combinación de estos dos personajes en la gestión del ayuntamiento municipal introdujo un profundo cambio en el funcionamiento del gobierno indígena, así como en su integración. En primer lugar, con la llegada de dos jóvenes trilingües se hizo innecesaria la presencia ladina en el puesto de secretario municipal, y se eliminaría el cargo. Adicionalmente, ambos personajes compartían el proyecto modernizador, con ideales de progreso. El profesor consideraba como legítimos y adecuados los principios indigenistas y compartía la filosofía integracionista. Mientras que el catequista era portador de una crítica hacia el sistema de dominación kaxlan 'ladino' sobre el indígena. Los ladinos eran vistos como responsables de la miseria indígena, además del racismo que sufría la población, esto según lo planteado por la pastoral liberadora de aquellos años.

Tras un proceso político iniciado apenas un año después (1981), estas autoridades municipales se propusieron terminar con lo que consideraban un «sufrimiento» para los tsotsiles, y pensaron poner fin a las fiestas católicas patronales y a las ancestrales. Se percibía que mediante las festividades patronales se enriquecían los comerciantes ladinos y se empobrecían los indígenas, por lo que decidieron que la celebración de las fiestas dejara de ser una tarea del ayuntamiento municipal. La razón del cambio era que pretendían que el ayuntamiento hiciera algo por el municipio y sus habitantes, y «no nada más fiesta». ${ }^{9}$ Para lograr ese cometido, y luego de una planificación detallada entre ambos funcionarios (presidente y juez municipales), decidieron decretar dos mandatos apoyados por «gobernación»: 1. No obligar a nadie a ejercer cargos fuera de su voluntad. 2. Remunerar económicamente a todos los que realizaran tareas en el ayuntamiento municipal. Este decreto tuvo diversas consecuencias. Una de ellas fue la crisis en las finanzas municipales, pues de acuerdo con el mandato se tenía que pagar por sus servicios desde a los mayoletik 'policías' hasta al peserente

\footnotetext{
${ }^{9}$ Entrevista con Pedro García Huacash, San Andrés Puerto Rico, Huixtán, Chiapas, febrero de 2012.
} 
'presidente municipal', pasando por alkalte 'alcaldes', regiroltik 'regidores' municipales y regionales, síndicos y secretarios municipales. En general se debía pagar a todos los funcionarios que hasta ese momento permanecían únicamente como «servidores» tanto de la comunidad como de los santos y de las deidades ancestrales. Pero las finanzas municipales no pudieron sostener a ese numeroso ayuntamiento, y a partir del año siguiente (1982) se tomaran nuevas medidas para reducir el número de funcionarios en el ayuntamiento huixteco, ${ }^{10} \mathrm{y}$ únicamente se mantuvo al cuerpo de ancianos principales, por la importancia que suponían para el gobierno. Esto sucedió hasta finales de la década de los ochenta. ${ }^{11}$

Estas medidas fueron acompañadas por un enfoque modernizador en el número de miembros que integrarían el ayuntamiento municipal, así como su diseño, y se produjo un proceso de desindianización en el concepto de la autoridad. Por ejemplo, se uniformó a los mayoletik y fueron nombrados policías municipales. En el ajuste del número de miembros del ayuntamiento se eliminó a los cuatro regiroletik tradicionales, y se limitó su número a cuatro regidores municipales. Estos tuvieron que asumir la doble función, tanto de labores administrativas como de las propiamente religiosas de las que se encargaban los regidores regionales (del antiguo ayuntamiento regional). También se eliminaron los cargos de alcaldes, y sus funciones fueron asumidas por el presidente municipal, quien además de las tareas administrativas retomó objetos simbólicos y reprodujo prácticas sociales, discursos y responsabilidades (políticas y religiosas) que realizaba el antiguo alcalde. Al hacerlo, se apropió de uno de los dos bastones de mando, y lo asumió como parte de su indumentaria, que había pertenecido únicamente al alcalde

${ }^{10}$ Ante tal situación, el presidente municipal gestionó los salarios correspondientes y los apoyos económicos para las celebraciones con el gobierno del estado encabezado por Juan Sabines Gutiérrez, quien en 1982 aportó $\$ 200000.00$ pesos para la realización de la «costumbre» (Pineda 1993:164). De acuerdo con la versión del entrevistado, los pagos a los funcionarios del ayuntamiento comenzarían un año más tarde, al término del periodo de Pedro García Martínez, a partir de 1983.

${ }^{11}$ «Los cargos del gobierno de los principales son de carácter sagrado, y a ellos llegan los jefes de linaje después de haber servido durante largo tiempo a la comunidad en las funciones inferiores del gobierno regional o constitucional, y luego de haber demostrado con hechos que son poseedores de un conocimiento místico que los capacita para el trato con lo sobrenatural» (Aguirre 1991:99). hasta 1982. Actualmente, este bastón de mando es parte vital de su indumentaria por su importancia simbólica como fuente de legitimidad como autoridad máxima del gobierno indígena, aun cuando se trate del presidente municipal.

Estos cambios realizados en el gobierno municipal se acomodaron también a las necesidades políticas del Estado en el proceso de «modernización» emprendido por el gobierno neoliberal de Miguel de la Madrid (1982-1988), durante el cual se decretó, en 1983, la reforma al artículo 115 constitucional, por la cual se permitió mayor «autonomía política» a los municipios del país dentro del marco jurídico que hasta entonces asumían con un papel únicamente administrativo, reformas que devolvían, según la proclama, la concepción originaria del municipio como base de la organización política y administrativa del Estado. ${ }^{12}$ Hay que decir que las configuraciones en la estructura de gobierno municipal huixteco en 1982, y el decreto de 1983, representaron para los pobladores de ese municipio un intento de «modernización», que no significó, sin embargo, la democratización de la vida política municipal de Huixtán, y aunque considero que las directrices de cambio en la estructura del gobierno huixteco respondían en parte a una insurrección civil de la población para hacer valer su derecho a gobernar su municipio de acuerdo con los estatutos de la Ley Orgánica Municipal, las nuevas configuraciones presentadas en la institución de gobierno municipal tuvieron, como durante el cardenismo a finales de los años treinta, relación con un contexto más amplio y el impulso de la combinación de todos los factores mencionados.

Así fue como al finalizar el siglo XX se produjo un proceso contradictorio. Por un lado el ayuntamiento constitucional se había «indianizado», porque estaba en manos indígenas, pero al mismo tiempo se producía un proceso de «desindianización», en cuanto a la integración de sus miembros y de su funcionamiento. Con estas dificultades, durante el siglo $\mathrm{XX}$ se dio paso a un tipo de gobierno indígena local que era, en parte, disímil (en sus tareas y responsabilidades de gobierno) del ayuntamiento constitucional establecido por el Estado, pero muy distinto también de lo que había sido el gobierno indígena con los antiguos cargos de origen colonial de gobierno. En este

${ }^{12}$ «Decreto por el que se reforma y adiciona el artículo 115» (Carmona 2013). 
sentido, había nacido una nueva forma de gobierno municipal en Huixtán. ${ }^{13}$

Es en este escenario donde el gobierno indígena y el gobierno municipal cobran renovado sentido al adaptarse al contexto de cambio transcurrido en Huixtán, lejos de los intentos de «modernización» emprendidos por el Estado asimilacionista, que promovió la desindianización de los funcionarios públicos y de los gobiernos indígenas a través de la eliminación de los antiguos funcionarios y cargos del gobierno indígena, y que para conseguirlo fortaleció la presencia del ayuntamiento municipal constitucional, como instancia única de gobierno en Huixtán, aunque, como veremos más adelante, sin conseguirlo completamente.

\section{LA REBELIÓN ZAPATISTA Y LA REINDIANIZACIÓN DEL GOBIERNO MUNICIPAL HUIXTECO EN LOS NOVENTA}

La etapa de finales de los años ochenta quedó marcada por un clima de inconformidad social ocasionado por las reformas neoliberales promovidas por el gobierno de Miguel de la Madrid, cuyas reformas hicieron necesario tomar drásticas medidas de austeridad económica que concluyeron, años más tarde, con la devaluación del peso y la eliminación de subsidios gubernamentales al campo (Collier 1998, Harvey 2000). Irónicamente, este contexto de crisis (además de un descontento social generalizado en la región) generó que los tsotsiles diversificaran su propia economía, lo que trajo consigo cambios no solo económicos sino también innovaciones sociopolíticas en la región, que derivaron en la rebelión del Ejército Zapatista de Liberación Nacional (EZLN), en 1994 (Collier 1998). Si bien la rebelión zapatista en Chiapas hizo visible una nueva geografía social y el cambio sociopolítico que los indígenas alteños adquirieron en el transcurso de la década (1983-1993), en Huixtán particularmente esta situación se situó en el cambio de tres principales aspectos: el agrario, el religioso y el político. Estos fenómenos sociales, derivados de la coyuntura abierta por el zapatismo, coadyuvaron inicialmente para que el ayuntamiento constitucional huixteco pasara por un nuevo proceso

\footnotetext{
${ }^{13}$ Conversación con Alonso Ton Pérez, barrio San Sebastián, Huixtán, Chiapas, febrero de 2012.
}

de «reindianización». ${ }^{14}$ Así, la reinvención, recuperación y posterior reapropiación de los aspectos ceremoniales y rituales por el ayuntamiento municipal no se consolidaron hasta plenamente entrado el siglo XXI, a causa de un largo proceso que inició después del levantamiento armado de 1994.

La cuestión agraria era un tema cerrado desde finales de los años setenta en el municipio, y al retomarse estas demandas a mediados de los noventa, las consecuencias fueron la recuperación (y posterior compra de predios) de tierras de forma organizada tras la contrarreforma agraria realizada por Carlos Salinas de Gortari entre los años 1992-1993. Este escenario dio como resultado nuevas localidades en el municipio, como Santa Rita y San Gregorio, hacia 1995. Algunas de esas nuevas comunidades, sin embargo, fueron resultado de un proceso contrario, pues tras la rebelión de 1994 el movimiento zapatista encontró fuerte simpatía y apoyo, y eso generó divisiones en ciertas comunidades, que al no estar de acuerdo con los planteamientos políticos zapatistas se separaron de sus comunidades con el apoyo del gobierno municipal priísta.

Pasado el levantamiento armado zapatista, una campaña de desprestigio emprendida por los religionetik 'presbiterianos' locales en contra de los católicos (bíblicos y tradicionalistas) recorrió el municipio. Se afirmaba en la localidad que «los católicos» habían apoyado la rebelión indígena, y con ello habían apoyado la «matanza de hermanos», y se decía que cómo era posible que «un hermano enseñe a matar a otro hermano»..$^{15}$ La Iglesia católica negó las acusaciones que se le imputaban, aunque como derivación de tal rumor la institución religiosa asumió la necesidad de difundir más su interés por retomar la religión indígena «tradicionalista» ancestral hacia 1996. Tal llamado costó en Huixtán nuevas inconformidades de parte de los católicos bíblicos, quienes a finales de los ochenta mantuvieron una fuerte postura crítica hacia las prácticas religiosas

\footnotetext{
${ }^{14}$ Un análisis pionero en este sentido puede encontrarse en Luis Vázquez de León (1992), quien hace referencia a un proceso de «purepechización» en las serranías del estado de Michoacán, como resultado de procesos de organización campesina en la región que permitieron una suerte de «reindianización o reavivamiento étnico», lo cual posibilitó un acceso a la tierra y a los bosques que dio paso a una economía basada en la explotación forestal.

${ }^{15}$ Entrevista con Antonio Trejo Trujillo, Huixtán, febrero de 2012.
} 
ancestrales y quienes entonces estaban convencidos de seguir su camino pastoral, que iniciaron desde los años sesenta en la región y el municipio (De Vos 1997, Sánchez 1997). Sobre el tema un testimonio relata este pasaje:

Porque antes los sk'op tios [católicos bíblicos] decían que qué íbamos a pedir a la cueva, qué te va a dar esa cueva, decían, lo único que te va a dar es un «aire», eso no es bueno, no vayan a hablarle. Pero ahora, la iglesia [católica] permite [las peticiones] después de que lo pensaron. Pero la gente dice: «primero viene [la iglesia] y lo desaparece, y luego, quiere que vayamos otra vez. No, así no es». Si no hubiera hecho eso, antes era mucho mejor, más grande [la celebración]. Porque iban al cerro, a rezar, a pedir agua para la milpa, al terminar en el cerro venían a la iglesia a pedirle favor al santo aquí en la cabecera. ${ }^{16}$

Sin embargo, las respuestas al llamado de la Iglesia católica no se hicieron esperar. A decir de Miguel Sánchez (2012), esto propició en los últimos años (a partir del año 2000) la posibilidad de eliminar las restricciones que existían entre católicos bíblicos y tradicionalistas, y de ese modo se permitió el diálogo y la coexistencia renovada entre uno y otro credo religioso en el municipio (Sánchez 2012:185).

Aun con estos incipientes cambios en el catolicismo, del rumor que había involucrado a los católicos huixtecos en los años noventa resultó un aumento en el número de protestantes y una reducción del número de feligreses católicos «tradicionalistas» a finales de los noventa, aunque paradójicamente se incrementó el número de católicos bíblicos, hasta el asesinato de 47 de estos en Acteal, Chenalhó, en diciembre de 1997. La noticia de este hecho significó para los protestantes la razón definitiva para incrementar el número de seguidores, como a inicios del siglo XX, y dejar en agonía casi absoluta a los católicos tradicionalistas, y en menor medida a los bíblicos. ${ }^{17}$

Cabe mencionar que en Huixtán las religiones protestantes tienen presencia desde mediados de 1950 (a inicios de los años sesenta conformaron la comunidad de Sba Sob, que hoy se conoce como

16 Entrevista con Miguel Martínez Pérez, Los Ranchos, Huixtán, Chiapas, 18 de febrero de 2012.

${ }^{17}$ Entrevista con Antonio Trejo Trujillo, Huixtán, febrero de 2012.
Bazom) ${ }^{18}$ Fueron hostigados y reprimidos por los «caciques» (comerciantes y artesanos) ladinos y por tsotsiles católicos «tradicionalistas» en sus inicios, y después de 1982 se dan las primeras expulsiones como consecuencia de las reconfiguraciones experimentadas por el gobierno indígena huixteco. Actualmente, en Huixtán existe un número creciente de conversos al protestantismo. Sin embargo, son únicamente indígenas (tsotsiles y tseltales), pues los ladinos han establecido que en la cabecera municipal (y en comunidades donde existen asentamientos de familias ladinas) no se permite construir templos evangélicos, como estrategia para mantener al catolicismo como único credo religioso. En otro orden, el final de la década de los ochenta y el inicio de los noventa fue también un periodo de transformaciones políticas profundas en los municipios alteños, y el de Huixtán no fue la excepción. En este contexto, la cuestión del gobierno indígena parecía ser un tema cerrado en Huixtán desde su configuración, en 1982, y hasta después de transcurrido el levantamiento zapatista.

La madrugada del 1 de enero de 1994, contingentes de hombres y mujeres indígenas militantes del autodenominado EZLN tomaron siete cabeceras municipales del estado, entre ellas la de Huixtán. A diferencia de lo acontecido en municipios como San Cristóbal, Ocosingo y Margaritas, la toma de Huixtán se realizó sin enfrentamiento alguno. De hecho, a pesar de que la ocupación se realizó en dos madrugadas, no fue sino hasta el día 7 que las fuerzas castrenses arribaron al lugar, cuando los milicianos zapatistas habían recibido la orden de retirada, después de haber permanecido tres días en la cabecera. Durante esa estancia los milicianos no hicieron sino repartir volantes con información de lo que acontecía allí y en otros municipios del estado. Asimismo, recorrían los barrios de la cabecera en una camioneta e iban informando las razones de su presencia: exigían «más justicia» y mejoras en el municipio, y afirmaban: «todo va a cambiar». ${ }^{19}$

\footnotetext{
${ }_{18} \mathrm{Sba}$ Sob es la denominación original de esta comunidad, aunque hoy es llamada Bazom. Por tratarse aquí de una aproximación etnográfica, retomo su nombre en tsotsil, que significa 'lugar donde amanece antes/primero', muy probablemente debido a que esta comunidad se ubica en una de las partes más altas del municipio huixteco y del altiplano central de Chiapas.

${ }^{19}$ Entrevistas con Antonio Trejo Trujillo, febrero de 2012, Huixtán, Chiapas, y con un exmiliciano zapatista, quien solicitó se omitiera su nombre y se utilizara el seudónimo de Miguel.
} 
El plano político se complejizó igualmente tras el levantamiento armado en el municipio. La militancia zapatista de la región conformó lo que llamaron una «segunda etapa de organización» política. Fue así como, en las inmediaciones del año 1996, se inicia el proceso de conformación del Municipio Autónomo Rebelde Zapatista (MAREZ) «Cabañas» de la Región Autónoma Pluriétnica Zapatista (RAPZ) Tzotz Choj que en 1996 se encontraba conformado por comunidades de los municipios de Ocosingo, Altamirano, Oxchuc, Chanal, Tenejapa, Cancuc, Amatenango de Valle, San Cristóbal de Las Casas y Huixtán. Su objetivo consistía entonces en que los militantes zapatistas pudieran «tener la libertad de autogobernarse y promover su desarrollo» lejos de sus ayuntamientos municipales. ${ }^{20}$ Así, la ranchería San Andrés Puerto Rico fue la localidad para establecer la cabecera del municipio autónomo, ubicada a escasos cinco kilómetros de la cabecera municipal de Huixtán. Ante el reto autonómico, el ayuntamiento municipal en poder del PRI tuvo que diseñar nuevas estrategias políticas para legitimar su permanencia como instancia única de gobierno del municipio, sobre todo tras la conformación de las semillas de las Juntas de Buen Gobierno (JBG) a mediados de los noventa, estrategia con que el gobierno priísta minimizó la importante presencia zapatista. ${ }^{21}$

Eran tiempos en que por vez primera se observaba la cultura de los pueblos indígenas con una lente que proponía la posibilidad de que pudieran formar parte (jurídicamente reconocidas) del presente político y no solo de la estantería de los museos y de las páginas de los libros de historia de un pasado remoto, como hasta entonces era percibida la cultura indígena. En ese sentido, el zapatismo, los movimientos y líderes sociales alteños que surgieron durante la década de los noventa y años posteriores, vieron su propia cultura no como algo a desechar en aras de la «modernidad», sino como algo que podía incluirse dentro de su quehacer político local, y alejarse de esta manera de los confines del olvido, de los lugares recónditos de la memoria, como ocurría en Huixtán durante los noventa.

\footnotetext{
${ }^{20}$ En 2003 pasó a conformar una Junta de Buen Gobierno (JBG). Aunque desde ese año sufre un paulatino debilitamiento, es posible observar su presencia viva en tiempo reciente (entrevista con Miguel).

21 Véase al respecto la nota de Hermann Bellinghausen (2012).
}

Al darse la declaratoria para conformar territorios y gobierno autónomos en las mediaciones del municipio, el priísta Nicolás Lorenzo Álvarez Martínez (1996-1998), con el afán de ganar legitimidad para su gobierno, obsequia a los pobladores del barrio una réplica, traída de Guatemala, de San Sebastián Mártir, con el compromiso de que se hiciera una procesión que iniciara en el ejido Lázaro Cárdenas (lugar en que el PRI tiene un fuerte arraigo), hacia la ermita del barrio de San Sebastián. Para darle mayor realce a esta nueva práctica religiosa que pretendía instaurarse, se solicitó que la procesión fuera dirigida por los ancianos principales. Dicha procesión fue realizada en enero de 1998 según el compromiso. ${ }^{22}$

A partir de entonces, el gobierno municipal ofreció apoyar la realización de los festejos a San Sebastián cada 20 de enero, compromiso que se extendió hacia otras celebraciones religiosas, y de esta manera se fue revitalizando - a solicitud expresa de comunidades y barrios- de nueva cuenta la realización de las fiestas católicas patronales de la cabecera municipal $\mathrm{y}$ de las ceremonias religiosas de las comunidades que hacía más de una década no se efectuaban, ${ }^{23}$ renovando con ello el vínculo de participación del ayuntamiento en esas prácticas. Esta revitalización promovida por el ayuntamiento, como parte de una estrategia política para ganar legitimidad en una situación de crisis política interna, por motivo de la militancia zapatista que había en el municipio, constatada con la instauración de un municipio autónomo en el territorio municipal, reincorporó también su relación con los principaletik como únicos guías ceremoniales de tales celebraciones. Esta acción del ayuntamiento municipal priísta revitalizó a la numerosa feligresía católica, en tanto que restó importancia a la organización zapatista en el municipio.

Otros factores contribuyeron. El obispo Samuel Ruiz García visitó Huixtán el 18 de enero de 2000, con el propósito de ordenar a 103 diáconos indígenas en la iglesia del santo patrono San Miguel Arcángel. La Iglesia católica conjuntó a los ancianos principa-

\footnotetext{
${ }^{22}$ Conversación con Manuel Moshán, barrio San Sebastián, Huixtán, Chiapas, febrero de 2012.

${ }^{23}$ Miguel Sánchez (2012:183-185) plantea también que en 1998 una fuerte sequía, que duró meses, azotó al municipio y provocó que se postergara la siembra, lo cual permitió que en algunas comunidades se retomaran casi de manera generalizada las celebraciones en sus principales ojos de agua y demás lugares sagrados. Entrevistas a Manuel Moshán y Alonso Ton Pérez, barrio San Sebastián, Huixtán, Chiapas, febrero de 2012.
} 
les, a las autoridades municipales, a los tunneletik 'diáconos' o 'servidores' y a las autoridades comunitarias, es decir, al conjunto de autoridades locales «tradicionales» y no «tradicionales», en un evento religioso. Hay que destacar que el obispo Samuel Ruiz no presidía en el municipio una ceremonia equivalente desde 1961, cuando realizó su primera visita a Huixtán en medio de una liturgia con características completamente distintas (Sánchez 1997:116).

Esta visita de Totik Samuel y el obsequio del santo, de parte del gobierno prísta apenas dos años antes, adquirieron mayor peso político para el ayuntamiento municipal, pues durante la realización de este evento se visibilizó públicamente, y quizá por vez primera, la resignificación que estaban viviendo las autoridades municipales y las comunitarias (agentes, comisariados, comités), pues durante el evento mencionado asumieron la representatividad de las comunidades como lo hacían las antiguas autoridades del gobierno indígena antes de los procesos de desindianización, al tomar muchas de sus características, símbolos y prácticas, guiados por el conocimiento que habían guardado los ancianos y por la participación de numerosos ancianos principales. Uno de estos símbolos fue la incorporación de las banderas de las comunidades y de los barrios. ${ }^{24}$

En un contexto de creciente politización y de una revitalización de la identidad y las instituciones indígenas, en el mismo año 2000 se presentó un conflicto político que condujo a la destitución del presidente municipal Samuel Hernández (PRI), quien apenas un año antes había asumido el cargo. Su destitución fue seguida por la del síndico municipal Belisario Pérez, a quien acusaron de «no cumplir las promesas de construir obras de beneficio social en la zona rural» y de no atender a la población en el Kavilto 'ayuntamiento' ni presentarse a laborar en el municipio. ${ }^{25}$ Fue significativo que esas acciones se tomaran revitalizando la práctica asamblearia: 42 de las

\footnotetext{
${ }^{24}$ Véase la nota de Blanche Petrich (2000).

${ }^{25}$ En Huixtán la destitución de los presidentes es una práctica política conocida desde finales de 1980. Otro ejemplo de ello fue la destitución de Pedro Pérez Martínez hacia 1985, un tsotsil originario de la comunidad de Bazom (Sba Sob), quien una vez electo fue sustituido, sin haber tomado posesión aún, por mandato de «la gente que no lo quería». Fue remplazado por Feliciano Muñoz (1985-1987). Hay que decir que Bazom es la primera comunidad del municipio huixteco con población mayoritariamente presbiteriana. Entrevista con Manuel Martín Icó, San Cristóbal de Las Casas, Chiapas, diciembre de 2012. Sebastián Bolom Pale, presidente del Comité Directivo
}

48 comunidades (entonces existentes) destituyeron a los funcionarios municipales. Dicha exigencia llevó a dejar como interino a Nicolás Martínez Gómez (2000-2001), del mismo partido, quien concluyó el trienio no sin dificultades. Esta tensión, aunada a la paulatina pérdida de control político del PRI en las comunidades y la fuerza política del zapatismo en el municipio, por esos años, obligaron a Javier Martínez Vargas (2002-2004), entonces presidente municipal (también por el PRI) a que asumiera la necesidad de entablar nuevas relaciones políticas dentro del municipio, incluso con los zapatistas, con quienes luego de buscar infructuosamente aliarse, finalmente no logró articular acuerdos. ${ }^{26}$

A inicios del año 2000 el debilitamiento del partido oficial y de la bases de apoyo zapatistas eran evidentes en el municipio, y fueron visibles después de la conformación de la JBG en 2003 y la llegada de infraestructura escolar a San Andrés Puerto Rico de parte del gobierno federal, que satisfacía una de las viejas quejas de la comunidad, por el abandono en el que sentían haber permanecido. ${ }^{27}$ En cambio, la principal fuerza política del partido de oposición, el Partido de la Revolución Democrática (PRD), junto con la revitalización de las prácticas ceremoniales y la organización política de las comunidades, parecían tomar cada vez mayor importancia.

La crisis política del PRI local, la presencia zapatista y la revitalización de la Iglesia católica en el municipio crearon un contexto favorable al PRD. Este había optado por una articulación con las organizaciones sociales desde inicios de los noventa. Y después de los cambios que ocurrieron en Huixtán, exmilitantes zapatistas y perredistas pasaron a conformar una sola organización política denominada

Municipal del PRI, Huixtán, Chiapas, febrero de 2012 (véase también Ángeles Mariscal y Elio Henríquez 2000).

${ }^{26}$ Es de resaltar que esta relación entre ayuntamiento municipal y bases de apoyo zapatistas intentó ir más allá de Huixtán, tal vez por la coyuntura electoral de 2004 . Entre el 8 y el 10 de agosto de 2003, en el hasta entonces Aguascalientes de Oventic, se celebraría la fiesta del nacimiento de los Caracoles y las Juntas de Buen Gobierno (JBG) zapatistas, como culminación de una serie de cambios surgidos en el EZLN y los 27 Municipios Autónomos Rebeldes Zapatistas (MAREZ). Durante dicho proceso, «miembros del PRI se desplazan desde Oxchuc, Huixtán [...] para estar presentes: también ellos quieren un gobierno de ellos mismos». Entrevista con Pedro Huacash, San Andrés Puerto Rico, febrero de 2012 (véase también Hermann Bellinghausen 2012).

${ }^{27}$ Entrevista con Pedro Huacash, San Andrés Puerto Rico, febrero de 2012. 
Frente de Lucha Popular 29 de Febrero. Sumado a ello, la característica de que las comunidades hubiesen consumado tal acción de organizarse políticamente sugería que estas habían pasado por un proceso de re-organización política en los últimos años. ${ }^{28}$

Así, el PRD parecía contar desde finales de los noventa e inicios del 2000 con bases políticas a lo largo y ancho del municipio, y como producto de su andar con las organizaciones sociales desde su conformación, mantenía un enfoque político crítico y comprometido, esto de acuerdo con lo planteado por los integrantes del Frente de Lucha Popular 29 de Febrero. ${ }^{29}$

Esta nueva fuerza política se hizo notar en otras luchas, por ejemplo, en la defensa del agua en el municipio en 2002, amenazada de privatización por la Coca-Cola. La población salió a la defensa del manantial, alegando que era un «lugar sagrado» para los tsotsiles huixtecos. ${ }^{30}$ Esta lucha, las prácticas y los discursos que se pronunciaban, eran expresión de que la identidad había pasado a ser parte de la resistencia política: si bien antes había sido utilizada por los zapatistas y las organizaciones sociales en la región Altos, en Huixtán era un hecho reciente para entonces.

Este proceso de revitalización de la identidad étnica ha ido en crecimiento y junto con ello ha habido cambios en las prácticas y los discursos de los miembros del ayuntamiento para sumarse a las actividades ceremoniales y religiosas. Por ejemplo, desde mediados de la década de los noventa, en Mulino Xchey 'El manantial' había un sistema de agua para abastecer a algunas comunidades del municipio de Oxchuc, y desde entonces las autoridades municipales oxchuquences realizan una ceremonia religiosa en el lugar, junto con los principaletik y la población huixteca. Pero las autoridades municipales de Huixtán habían estado ausentes. No es sino hasta 2007 (después de la instalación del sistema de agua potable y de la llegada del PRD al ayuntamiento mu-

\footnotetext{
${ }^{28}$ En sus inicio, la organización política tuvo presencia en localidades como San Andrés Puerto Rico, Adolfo López Mateos, barrio La Pila, Ch'enpil y Jok'osik. Pero en los últimos años se ha extendido por 16 comunidades más, llegando hasta el ejido Lázaro Cárdenas, Chilil, donde anteriormente sus habitantes eran exclusivamente prístas. Hay que agregar que los integrantes de dicha organización son mayoritaria pero no exclusivamente perredistas.

${ }^{29}$ Entrevista con David Gómez Díaz, CIDECI Las Casas, 2008.

${ }^{30}$ Véase más ampliamente Valadez 2007, ahí se documenta el proceso mencionado.
}

nicipal en Huixtán) que las autoridades municipales se sumaron a la mencionada celebración religiosa, que se realiza cada 4 de mayo en agradecimiento al Ch'ul Ojov 'rayo sagrado' que, de acuerdo con lo dicho por los huixtecos, habita en el manantial, en agradecimiento por el agua que brinda a ambos municipios, lo que a su vez da lugar a una nueva relación entre los «gobiernos indígenas municipales» y los lugares sagrados ancestrales.

En 2005, resultado de la reorganización política en las comunidades y la unificación de las fuerzas políticas del municipio (del PRD y las organizaciones sociales), se da a conocer públicamente el surgimiento del Frente de Lucha Popular 29 de Febrero, que se define como una organización política independiente, cuyo programa de «lucha y resistencia», a decir de uno de sus dirigentes, es «para manifestarse por las altas tarifas de la luz que cobra la Comisión Federal de Electricidad (CFE) en el municipio, que es uno de los más pobres de la zona». ${ }^{31}$ Así fue como esta organización llegó para hacer visible el cambio sociopolítico, que se consolidó cuando, en 2007, el PRD obtiene la presidencia municipal aprovechando fracturas internas en el PRI municipal. ${ }^{32}$

Los cambios en el poder municipal reconfiguraron las relaciones de poder en los ámbitos comunales y municipales. Por vez primera en la historia del municipio gobernaba un partido distinto del oficial, encabezado además por un huixteco tseltal (en un municipio de mayoría y hegemonía tsotsil), lo que significó que estábamos hablando no solamente de un ayuntamiento en manos indígenas, sino con una composición étnicamente diferenciada, legítimamente reconocida y aceptada. Asimismo, en esos comicios electorales de 2007 ocurrió que los mecanismos para la elección de las autoridades municipales denominadas por «usos y costumbres» estuvieron fuertemente articulados con los mecanismos electorales partidarios, a diferencia de lo que sucede en otros municipios del país, como los del estado de Oaxaca, donde «usos y costumbres» y partidos políticos son cosas completamente distintas, muchas veces incompatibles (Burguete 2013).

\footnotetext{
${ }^{31}$ Entrevista con David Gómez Díaz, CIDECI Las Casas, 2008.

${ }^{32}$ Entrevistas con Sofía Gómez Huacash, regidora plurinominal del PRI (2010-2012), Huixtán, Chiapas, 8 de marzo de 2012; Sebastián Bolom Pale, presidente del Comité Directivo Municipal del PRI, Huixtán, Chiapas, febrero de 2012.
} 
Así, durante el gobierno del profesor tseltal Ignacio Álvarez Pérez (2007-2010), la lucha de resistencia contra las altas tarifas de la luz eléctrica de la CFE incrementó su número de adherentes, llegando incluso a contar con el ayuntamiento municipal, y se sumaron otros actores antes no movilizados, como las comunidades presbiterianas o de predominancia de militantes priístas, como el ejido Lázaro Cárdenas, Chiliil. ${ }^{33}$ Alentado por su orientación ideológica de izquierda, y por haber surgido de las filas del PRD y del Frente de Lucha Popular 29 de Febrero, durante su gestión de tres años Ignacio Álvarez continuó con las prácticas religiosas ceremoniales heredadas de los gobiernos municipales prí́stas de los años noventa, las afianzó y reorganizó, y participó en ceremonias consideradas ancestrales, dotándolas de nuevos contenidos. ${ }^{34}$ Así, en la actualidad es posible observar las procesiones católicas encabezadas por las autoridades municipales, junto con los ancianos principales, por las calles de los barrios y en los lugares con significado religioso del municipio.

Hay que decir que si bien estas prácticas fueron promovidas con mayor ímpetu por el ayuntamiento después de 2007, estos impulsos parecían no tener un solo origen ni limitarse a las autoridades municipales. Sobre el tema nos comentó también un dirigente tsotsil del Frente de Lucha Popular 29 de Febrero:

[...] ya se estaba perdiendo la memoria, ya estábamos agarrando otras cosas, otras costumbres, pero precisamente en esta lucha de resistencia también se está empezando a hablar de las costumbres, de la comunidad. En nuestras reuniones se ha tratado también de eso, hay que volver a retomar algunas cosas que tiene las tradiciones, los costumbres de la gente, también allí el presidente municipal [Ignacio Álvarez] está promoviendo un poquito, las formas de hacer la comida como el atol agrio, como la chicha como eso que ya nunca se hacía, sin embargo ahorita se está promoviendo de nuevo, no sé hasta dónde va a llegar eso... porque cuando se habla de las comunidades, cuando se habla de los nuestro, de lo

${ }^{33}$ Muestra de ello es que, a finales de 2012, la CFE cobró al municipio poco más de nueve millones de pesos, cantidad acumulada de periodos de gobierno anteriores al actual (2013), que representa la cuarta parte del presupuesto anual de la alcaldía. Esto sucede aun cuando Huixtán se encuentra ubicado entre los municipios con mayor índice de marginalidad y pobreza de la entidad. Conversación con Cándido Díaz López, cuarto regidor propietario (2010-2012) por el PRD, Huixtán, Chiapas, febrero de 2012. Véase al respecto diario Cuarto poder (2013).

${ }^{34}$ Entrevista con Miguel Martínez Pérez, Los Ranchos, Huixtán, Chiapas, febrero de 2012. propio, pues son esas cosas, es muy difícil de reconstruir de nuevo eso, es la cosa. ${ }^{35}$

En otro testimonio se afirma al respecto:

[...] cuando yo nací ya estaba la fiesta. Antes no había concurso, era así nada más, no como ahora que manda el presidente [municipal]. La fiesta iba desapareciendo. Los sacristanes, por ejemplo, apenas hace unos dos o tres años comenzaron a juntarse de nuevo. Los de Chilil [ejido Lázaro Cárdenas] lo seguían haciendo, pero ya no venían a la cabecera, así como ahora, sino que hacían la fiesta allí en Chilil mismo, bajaron [a la cabecera municipal] hasta que hicieron el concurso, vinieron los de Chilil, antes no venían porque ya no estaban los que les decíamos regionales [ayuntamiento regional]. Dejaron de hacer la fiesta porque la gente cambió. Cambió el saludo con los ancianos, con las mujeres también, cambió todo, ya no sabían cómo saludar [saludo ceremonial muk'ta pat ontonal]. Por eso se había dejado de hacer la fiesta, porque todo cambió, por eso desapareció [...] ahora están impulsando la realización de fiestas en las cuevas, hacen fiestas en los cerros, en los ojos de agua, en lugares donde de por sí íbamos. Porque antes nuestros abuelos y abuelas se juntaban para hacer fiesta, tocaban tambor, subían cuetes, tenían cruces [los lugares donde iban], adornaban sus cruces y pedían perdón, pedían que viniera el agua, que no se acabara de granizo la milpa, los antiguos llevaban pox [aguardiente o trago] allí, así como se hace ahora [...] Cuando empecé de nuevo, como en el 2000, parece, ¡dios!, había como dos o tres nada más. Así empezamos otra vez, así empezamos. Así es como fue apareciendo nuevamente, poco a poco. Cuando empezamos, éramos mayoría de Los Ranchos, los de [Adolfo] López Mateos eran muy pocos. Los de Chilil ya ni venían, ellos fueron quienes vinieron ya cuando había concurso, lo mismo San Sebastián y La Pila. La fiesta desapareció varios años, porque cuando la fiesta volvió aquí, volvió a aparecer también en Nuevo Huixtán, allá, pasando el municipio de las Margaritas, rumbo a Pacayal. ${ }^{36}$

De acuerdo con esta versión, la recuperación, realización y resignificación de las celebraciones religiosas venían conformándose tiempo atrás, impulsados por agentes e intereses varios, como políticos y religiosos, como del ayuntamiento y de las comunidades. Como hemos visibilizado en este texto, estos cambios fueron iniciados a finales de los años noventa por iniciativa de la Iglesia católica en un intento por frenar el aumento de feligreses protestantes en el municipio, así como del prí́smo local, que encontró en esta revitalización religiosa una posibilidad para lograr su legitimidad como institución única de gobierno, cuando los zapatistas lo

\footnotetext{
${ }^{35}$ Entrevista con David Gómez Díaz, CIDECI Las Casas,

${ }^{36}$ Miguel Martínez Pérez, Los Ranchos, Huixtán, Chiapas, 18 de febrero de 2012.
} 2008. 
interpelaron al instaurar gobiernos paralelos, con las semillas de las Juntas de Buen Gobierno en Huixtán (JBG) en el municipio.

En este proceso de reindianización de las prácticas del gobierno municipal se han revitalizado/resignificado otras. Por ejemplo, la realización del k'exeltik 'ceremonia de cambio de autoridades' es un evento renovado desde el periodo 2010, cuando Ignacio Álvarez cedió el cargo al perredista tseltal Carlos Pérez (2010-2012). Antes de esto la ceremonia había perdido casi por completo su sentido ritual. En la ceremonia de transferencia del poder el presidente municipal recibe el bastón de mando, ícono que antes portaban los alkaltetik. Este ritual se mantuvo hasta el cambio de gobierno en 2012, con el profesor tsotsil Waldo Martín Pérez Bautista (2012-2015). En esta oportunidad hubo una innovación. Por primera vez algunos principaletik tsotsiles y un grupo de ch'uy k'aaletik 'rezadores' tseltales, además de presenciar la misa católica en la iglesia del santo patrono San Miguel Arcángel, como era realizado por los gobiernos priístas, efectuaron también una ceremonia retomando rituales ancestrales tsotsiles y tseltales. Asistieron las 52 autoridades comunitarias (comités, agentes municipales, juntas de festejos) y 19 autoridades agrarias (comisariados ejidales y un comisariado comunal) del municipio, conformando una suerte de «ayuntamiento ampliado» tal y como sucede en otros municipios alteños. ${ }^{37}$ Es necesario apuntar que en esta última ocasión el k'exeltik, realizado el 1 de octubre de 2013, coincidió con el fin de la celebración a San Miguel Arcángel, patrono del municipio, el 29 de septiembre, lo que provocó que se prolongara.

Es importante decir que si bien la conformación del ayuntamiento huixteco es tal cual los parámetros del Estado, es decir, como ayuntamiento constitucional, en un diseño de municipio libre, desde su configuración en 1982, en los hechos sus tareas y responsabilidades han ido más allá de lo que establecen las normas constitucionales. Así, los regidores municipales no se limitan a formar parte del ayuntamiento y cumplir con comisiones, sino que su representación está territorializada y cumplen con la representación de sus comunidades dentro del

\footnotetext{
37 Véase el caso de Chalchihuitán analizado por Araceli Burguete (1999b).
}

ayuntamiento. ${ }^{38}$ Estos regidores continúan ejerciendo tareas de impartición de justicia en el Kavilto, a pesar de que en el municipio existe desde 1999 un Juzgado de Paz y Conciliación Indígena. Asimismo, los regidores continúan realizando funciones religiosas, tal y como lo hicieron varias décadas atrás. En este proceso de reindianización, los regidores han recuperado sus funciones como organizadores (en coordinación con las diferentes juntas de festejos) de celebraciones religiosas locales, organizados ahora por la Comisión de festejos. Adicionalmente, los policías municipales cumplen tareas de los antiguos mayoletik, pues en la actualidad son guardias y servidores del presidente y de los regidores municipales, motivo por el cual suelen estar presentes durante cualquier actividad ceremonial o política.

Transcurrido el tiempo desde 1982, el ayuntamiento solo tuvo funcionarios tsotsiles huixtecos y se excluyó de igual modo a los tseltales y ladinos a pesar de su larga permanencia en el municipio. La inclusión de tseltales y ladinos en el ayuntamiento se da tardíamente hacia inicios del nuevo siglo. En este sentido, vale la pena agregar también que si el cuerpo de principaletik ha sido revitalizado en los últimos años y es de capital importancia para el gobierno municipal en sus tareas ceremoniales, su renovada presencia no significó la exclusión de la participación de los jóvenes, ni de los protestantes o los católicos bíblicos, como comúnmente se ha pensado sucede con los gobiernos indígenas, sino, por el contrario, en la última década en Huixtán esta característica ha hilvanado un proceso inacabado de «democratización política»y de reindianización del gobierno municipal. La inclusión de las mujeres como integrantes del Kavilto tal vez sea un elemento de importancia a resaltar y considerar, pues aunque han comenzado a aparecer señales de su participación durante el periodo 2010-2012 en el municipio, son aún insuficientes. ${ }^{39}$

\footnotetext{
${ }^{38}$ Esto también ha sido observado en Huixtán por Araceli Burguete (2009) en el gobierno anterior (2007-2010).

39 Sofía Gómez Huacash, regidora plurinominal del PRI (2010-2012), es la primera funcionaria mujer en el municipio. Originaria del ejido Tselepat. Estuvo en el cargo un año y ocho meses durante el periodo de gobierno de Carlos Pérez (20102012). Comenzó en el Comité de Educación en su comunidad durante tres años para luego pasar a Contraloría Social del Procampo local por tres años más. Finalmente, producto de su afiliación al PRI municipal, es invitada para apoyar al candidato prísta a la Presidencia Municipal, que no gana los comicios y eso provoca en el PRI una fractura que abre el camino al PRD.
} 
Si bien al iniciar el siglo XXI, el principal partido político de oposición en el municipio (PRD) alcanzó una importancia política que trajo consigo una suerte de «democratización política», su impulso se debió en mucho, como he anotado ampliamente páginas atrás, a la coalición que mantuvo con las organizaciones sociales independientes y sus objetivos desde su fundación a finales de los ochenta. La coyuntura zapatista y los siguientes sucesos que marcaron la última década del siglo $\mathrm{XX}$ fueron de algún modo importantes para su continuidad, fortalecimiento y consolidación en el Huixtán del siglo XXI. Fue así como en 2007 el PRD llegó al poder municipal, con un nutrido proyecto político y amplias bases de apoyo a lo largo y ancho del municipio, en medio del debilitamiento de la bases zapatistas y la crisis interna por la que atravesaba el PRI no únicamente local sino también a nivel nacional. Sin embargo, es importante comprender que en los últimos años (2010-2012), ya en el poder, el PRD ha ido perdiendo aliados estratégicos que le permitieron tales logros, y poco a poco han ido surgiendo nuevas fracciones políticas dentro de sus filas, que muchas veces tienen un posicionamiento político distinto al que habían mantenido desde sus primero años. Muestra de ello es que tan solo en el trienio del gobierno anterior, varias comunidades han abandonado el PRD para afiliarse al PRI o al PAN. Sin mencionar que en últimas fechas el gobierno municipal en poder del PRD ha sido acusado (como antes sucedió con el PRI) de «desatender» a las comunidades del municipio.

Por el contrario, en los últimos años el PRI municipal atraviesa por un proceso de fortalecimiento $\mathrm{y}$ de reconstitución local, puesto que muchos de sus militantes se han reincorporado a sus filas. Asimismo, no hay que olvidar la importancia del resultado del proceso electoral federal de 2012 que llevó a la Presidencia de la República al candidato del PRI, Enrique Peña Nieto, que puede considerarse como un indicador con posibilidad de verse reflejado en los próximos comicios electorales en varios municipios del estado de Chiapas, incluido Huixtán. Así, aunque todo apunta hacia el regreso del PRI al

Tres años después, el PRD vuelve a ganar las elecciones municipales, aunque derivada de la reforma electoral 2007-2008 que modificó el porcentaje en una proporción de $60 / 40$ y con la recomendación de que se llegue a la paridad plena entre hombres y mujeres dentro de los partidos políticos, Sofía Gómez es invitada a ocupar la tercera regiduría plurinominal por el PRI, y de ese modo llegaría a ser la primera funcionaria municipal. poder municipal, la apuesta huixteca por la democratización o construcción de un gobierno que responda a sus necesidades y aspiraciones a través de la competencia electoral vía los partidos políticos tendrá frente a sí un renovado y complejo escenario político que los huixtecos definirán en los próximos años.

\section{REFLEXIONES FINALES}

Como hemos documentado en esta colaboración, pese a la temprana presencia ladina en el municipio de Huixtán, lo que condujo a una desindianización del ayuntamiento municipal, en distintos momentos irrumpen procesos para lograr de nuevo su reindianización, que ha consistido en que los indígenas recuperen para sí la representación y los cargos del ayuntamiento. Este proceso dinámico no ha sido lineal, sino que en la historia huixteca se presenta como un ciclo de distintos momentos de desindianización y reindianización, y de nuevo la desindianización, para de nuevo producirse la reindianización. En su última fase aparece como dato importante la coyuntura zapatista, después de 1994. Como hemos documentado, desde una perspectiva etnográfica con enfoque histórico, estos procesos no se desarrollan en aislamiento social, sino que, por el contrario, están articulados y se desarrollan en el marco de procesos nacionales y regionales. No obstante, las dinámicas internas que los producen adquieren gran importancia. Por ello, es indispensable apuntar también que los cambios internos responden a la relación entre las tramas sociales más amplias, las cuales son objeto de reinterpretación y cobran un nuevo sentido y singularidad en el municipio.

Desde esta óptica, considero que este proceso que denomino de reindianización del gobierno municipal, constituido de nuevo como «gobierno indígena» (aun cuando se trate de un municipio con presencia zapatista) articula en sus prácticas y discursos tanto al ayuntamiento constitucional como al cuerpo de autoridades tradicionales; expresa y articula una serie de elementos socioculturales ancestrales y del presente político que convergen en su reconfiguración constante. Se trata de una institución dinámica, cambiante, con reconocimiento de los indígenas huixtecos y aceptación de parte del Estado. En este orden de ideas, todo indica que el ayuntamiento municipal vuelve ser el espacio donde surgen y 
se desarrollan las luchas políticas y se revitaliza la identidad étnica, y las prácticas e instituciones de gobierno de los indígenas huixtecos. Asimismo, se evidencia la complejidad de la interrelación, adaptación y resistencia de los pueblos indígenas frente a las instituciones políticas y los espacios de gobierno. Quizás este proceso tenga que ver más con una toma de conciencia y revitalización étnica y no tanto con una llana filiación religiosa católica. Todo ello, ante la negativa del Estado de reconocer las instituciones del gobierno indígena, aun cuando están presentes en toda la región alteña.

\section{FUENTES DE CONSULTA}

Aguirre Beltrán, Gonzalo, 1991, Formas de gobierno indígena, FCE, UV, México.

Bellinghausen, Hermann, 2012, «Los cabildos oficiales, fantasmas ante el nuevo vigor de la autonomía india», La Jornada, en www.jornada.unam.mx/2003/08/08/012n1pol. php?origen $=$ politica.php\&fly $=1$ [consulta: 1 octubre de 2012].

Burguete, Araceli y Jaime Torres, 2007, «Remunicipalización en Santiago el Pinar: un empoderamiento acotado", en La remunicipalización de Chiapas. Lo político y la política en tiempos de contrainsurgencia, A. Burguete $\mathrm{y}$ X. Leyva (coords.), CIESAS/Porrúa/H. Cámara de Diputados LX Legislatura, México, pp. 135-178.

Burguete, Araceli, 1999a, «Empoderamiento indígena tendencias autonómicas en la región Altos de Chiapas», en A. Burguete (coord.), México: Experiencias de autonomía indígena, IWGIA, CECADEPI-RAP, Copenhague, pp. 283-300.

, 1999b, «Poder local y gobiernos indígenas en los Altos de Chiapas: sus retos en el futuro de México: El caso de Chalchihuitán», ponencia presentada en el congreso Gobiernos locales. El futuro político de México, 23 y 24 de septiembre, Red de Investigadores en Gobiernos Locales de México (IGLOM), Guadalajara, México.

, 2009, Monografía del municipio de Huixtán, Chiapas, documento inédito.

, 2011, «La indianización del gobierno municipal y la municipalización del gobierno indígena», en Revista Pueblos y Fronteras Digital,
2011, v. 5, n. 11, PROIMMSE-UNAM, pp. 38-88, en www.pueblosyfronteras.unam.mx/a $11 \mathrm{n} 11 /$ art_02.html [consulta: 23 junio de 2011].

, 2013, «Disputas en el terreno de la justicia electoral mexicana: nuevas herramientas para la lucha por el poder en Chamula, Chiapas», ponencia presentada en el $I X$ Congreso Centroamericano de Antropología, 18 al 22 de febrero, Universidad de San Carlos, Guatemala. Carmona Dávila, Doralicia, 2013, «1983. Decreto por el que se reforma y adiciona el artículo 115 de la Constitución Política de los Estados Unidos Mexicanos», en Memoria política de México, en www.memoriapoliticademexico. org/Textos/ 7CRumbo/ 1983DEf-CONst.html [consulta: 17 enero de 2013].

Collier, George, 1998, ¡Basta! Tierra y rebelión zapatista en Chiapas, UNACH/Food First Books, San Cristóbal de Las Casas.

Diario Cuarto Poder, 2013, «CFE cobra más de 9 millones de pesos a Huixtán»", en: www.cuartopoder.com.mx/\%5CPagPrincipal_Noticia. aspx ?idNoticia $=307241 \&$ idNoticiaSeccion=4\&idNoticiaSubseccion=16 [consulta: 1 enero de 2013].

Fuente, Julio de la, 1990, Relaciones interétnicas, n. 6, INI/Conaculta, México.

Gómez K'ulub, Manuel, Roberto Sántiz, Samuel Sántiz y Pedro López 2010, Kajwaltik ordenanza de la Colonia de 1674, CELALI/Coneculta, Tuxtla Gutiérrez.

Harvey, Neil, 2000, La rebelión de Chiapas. La lucha por la tierra y la democracia, Era, México.

INEGI, 1997, División territorial del estado de Chiapas de 1810-1995, Aguascalientes.

Lenkersdorf, Gudrun, 2001, Repúblicas de indios, UNAM, México.

Mariscal, Ángeles y Elio Henríquez, 2000, «Destituyen alcalde priísta en Huiztán por el sistema de usos y costumbres», La Jornada, en www.jornada.unam.mx/2000/09/12/031n2gen. html [consulta: 1 octubre de 2012].

Miller, Frank Charles, 1959, «Social structure and medical change in a Mexican Indian community», tesis de doctorado, Harvard University, Cambridge.

Moguel Viveros, Manuel y Roberto Parra Vázquez, 1998, «Los ladinos rurales de Huixtán y Oxchuc: un caso de involución social», en M. E. 
Reyes, R. Moguel y G. van der Haar (coords.), Espacios disputados. Transformaciones rurales en Chiapas, Universidad Autónoma Metropolitana-Unidad Xochimilco/ECOSUR, México, pp. 69-97.

Palomo, Dolores, 2009, Juntos y congregados. Historia de las cofradías en los pueblos indios tzotziles y tzeltales de Chiapas (siglos del XVI al XIX), CIESAS, México (Publicaciones de La Casa Chata).

Petrich, Blanche, 2000, «Ordenan a 103 parejas de diáconos y 53 de prediáconos», en: www.jornada.unam.mx/2000/01/24/ordenacion.html [consulta: octubre de 2012].

Pineda, Olivia, 1993, Caciques culturales (El caso de los maestros bilingües en los Altos de Chiapas), Altres/Costa-Amic, Puebla.

Pozas Arciniega, Ricardo, 1987, Chamula, INI, México.

Rus, Jan y Robert Wasserstrom, 1980, «Civilreligious hierarchies in central Chiapas: a critical perspective», American ethnologist, v. 7, n. 3, pp. 466-478.

Rus, Jan, 2004, «La comunidad revolucionaria institucional: la subversión del gobierno indígena, en los Altos de Chiapas, 1936-1968», en J. P. Viqueira y M. H. Ruz (eds.), Chiapas los rumbos de otra historia, CIESAS-/UNAM, México, pp. 251-278.

Salmerón, Francisco, 1964, «Huistán: su plaza ceremonial», en La palabra y el hombre, 30, abril-junio, Universidad Veracruzana, Xalapa, pp. 195-202.
Sánchez Álvarez, Miguel, 1997, Jok'osik una comunidad en transición, Gobierno del Estado de Chiapas, Coneculta/CELALI, Tuxtla Gutiérrez.

Sánchez Álvarez, Miguel, 2012, Territorio y culturas en Huixtán, Chiapas, UNICH/INALI/SCLC.

Siverts, Henning, 1964, Política y liderazgo en los Altos de Chiapas (1964), traducción de Leif Korsbaek y Laura Rincón Santiago, documento inédito.

__, 1965, El cacique de K'ankujk'. Un estudio de liderazgo y cambio social en los Altos de Chiapas, México (1965), traducción de Leif Korsbaek, documento inédito.

Valadez, Ana, 2007, «Refrescando viejas cuitas en la otrora Ciudad Real», en A. Barreda y E. Ortiz (coords.), Defensa y gestión comunitaria del agua en el campo y la ciudad Testimonios y diálogos sobre el metabolismo irracional del agua en México, Editorial Ítaca/Coalición Internacional para el Hábitat/Oficina de Coordinación Regional para América Latina/ Centro de Análisis Social, Información y Formación Popular, México, pp. 66-69.

Vázquez de León, Luis, 1992, Ser indio otra vez. La purepechización de los tarascos serranos, Conaculta, México.

Vos, Jan de, 1997, «El encuentro de los mayas de Chiapas con la teología de la liberación», en Eslabones, Revista Semestral de Estudios Regionales, n. 14, Instituto de Investigaciones Sociales/UnAM, México, pp. 88-101.

Wasserstrom, Robert, 1989, Clase y sociedad en el centro de Chiapas, FCE, México. 